\title{
Ground and excited-state electron-transfer reactions of a few (anthracen-9-yl)methanamines: a comparative study
}

\author{
Jomon P. Jacob, Ligi M. Lalu, Reshma Gopalakrishnan, Rekha R. Mallia, \\ Perupparampil A. Unnikrishnan, and Sreedharan Prathapan* \\ Department of Applied Chemistry, Cochin University of Science and Technology, \\ Cochin-682 022, Kerala, India. \\ E-mail:prathapans@gmail.com
}

DOI: http://dx.doi.org/10.3998/ark.5550190.p009.340

\begin{abstract}
Comparative study of chemical and light induced electron-transfer reactions of some (anthracen9-yl)methanamines is reported. Ceric ammonium nitrate was used to initiate chemically-induced electron-transfer reactions of anthracenemethanamines. Nitration at the 2-position followed by oxidation was the major pathway observed in the reaction with CAN while electron-transfer mediated $\mathrm{C}-\mathrm{N}$ bond cleavage followed by dimerization was the major pathway in photochemical reactions.
\end{abstract}

Keywords: Ceric ammonium nitrate, oxidation, nitration, anthracenemethanamines, electrontransfer reactions

\section{Introduction}

Ceric ammonium nitrate (CAN) is widely employed in organic synthesis. Most of its applications are based on its potential to act as either a single- or two-electron acceptor and low affinity towards oxygen. Several comprehensive reviews discuss the utility of ceric ammonium nitrate (CAN) in organic synthesis. ${ }^{1-4}$ Reaction of anthracene and its derivatives with CAN has attracted considerable attention. ${ }^{5,6}$ The radical cation of anthracene arising through single electron-transfer to CAN is an important intermediate in these reactions. Subsequently, both nitration and oxidation products are formed in the reaction between anthracenes and CAN. Oxidation and addition reactions of some anthracene derivatives with dimethyl malonate in the presence of CAN yielded products such as anthraquinone, bianthrone, 9-methyl-10-methoxyanthracene, 9methyl-10-oxo-9,10-dihydroanthracen-9-yl nitrate and 9-ethoxy-9-phenylanthrone. ${ }^{5}$

CAN-mediated highly selective debenzylation reactions of $N$-benzyl tertiary amines are wellestablished reactions. ${ }^{7-14}$ The efficiency of such debenzylations is a sensitive function of the 
nature of the $N$-substituents. ${ }^{7}$ Initial single electron transfer to CAN is invoked to account for the debenzylation process. Interestingly, secondary amines are inert towards CAN. Based on these observations, a viable protection/deprotection strategy for secondary amines has emerged: $\mathrm{N}$ benzylation followed by $\mathrm{CAN}$-mediated debenzylation completes the protection-deprotection sequence.

Recently, we unravelled an interesting single electron-transfer reaction between anthracenemethanamines and electron deficient acetylenes. ${ }^{15}$ Similar electron-transfer reactions were observed between anthracenemethyl sulfides and electron-deficient acetylenes. ${ }^{16}$ Single electron-transfer reactions between amines and electron acceptors such as $\mathrm{Cu}(\mathrm{II})$ perchlorate are well documented in the literature. ${ }^{17}$ The reduction potential for $\mathrm{Cu}(\mathrm{II})$ to $\mathrm{Cu}(\mathrm{I})$ is $0.15 \mathrm{~V}$ while that for $\mathrm{Ce}(\mathrm{IV})$ to $\mathrm{Ce}(\mathrm{III})$ is $1.61 \mathrm{~V}$. So, it is reasonable to assume that CAN can also initiate single electron-transfer mediated reactions with anthracenemethanamines ${ }^{18}$ and anthracenemethyl sulfides. ${ }^{19}$ Furthermore, anthracenemethanamines are benzylamine analogs that are likely to undergo $\mathrm{C}-\mathrm{N}$ bond cleavage in the presence of CAN as well as reactions characteristic of the anthracene component.

The photochemsitry of tertiary amines has also attracted considerable attention. ${ }^{20,21}$ Both inter- $^{22-24}$ and intramolecular ${ }^{25-29}$ electron and energy transfer, and exciplex formation ${ }^{24}$ take place between arenes and tertiary amines. Formation of intramolecular arene-amine exciplexes and their photophysical and photochemical behaviour have been of longstanding interest. ${ }^{23,29-34}$ Hence, anthracenemethanamines having both amine and arene components are appropriate substrates to examine intramolecular excited state electron-transfer reactions.

In the present investigation, we examined both CAN-mediated and photochemical transformations of several structurally diverse (anthracen-9-yl)methanamines. These systems are designed to unravel the effect of structure on both chemical electron transfer (CET) and photochemical electron transfer (PET).

\section{Results and Discussion}

(Anthracen-9-yl)methanamines 1a-k having diverse steric and electronic environments around the nitrogen atom were accessed through Leukart reactions between 9-anthraldehyde and appropriate secondary amines (Chart 1). ${ }^{15,35}$ CAN and light induced transformations of 1a-k were examined by product analysis. A general outline of our investigations and findings is provided in Chart 2. 

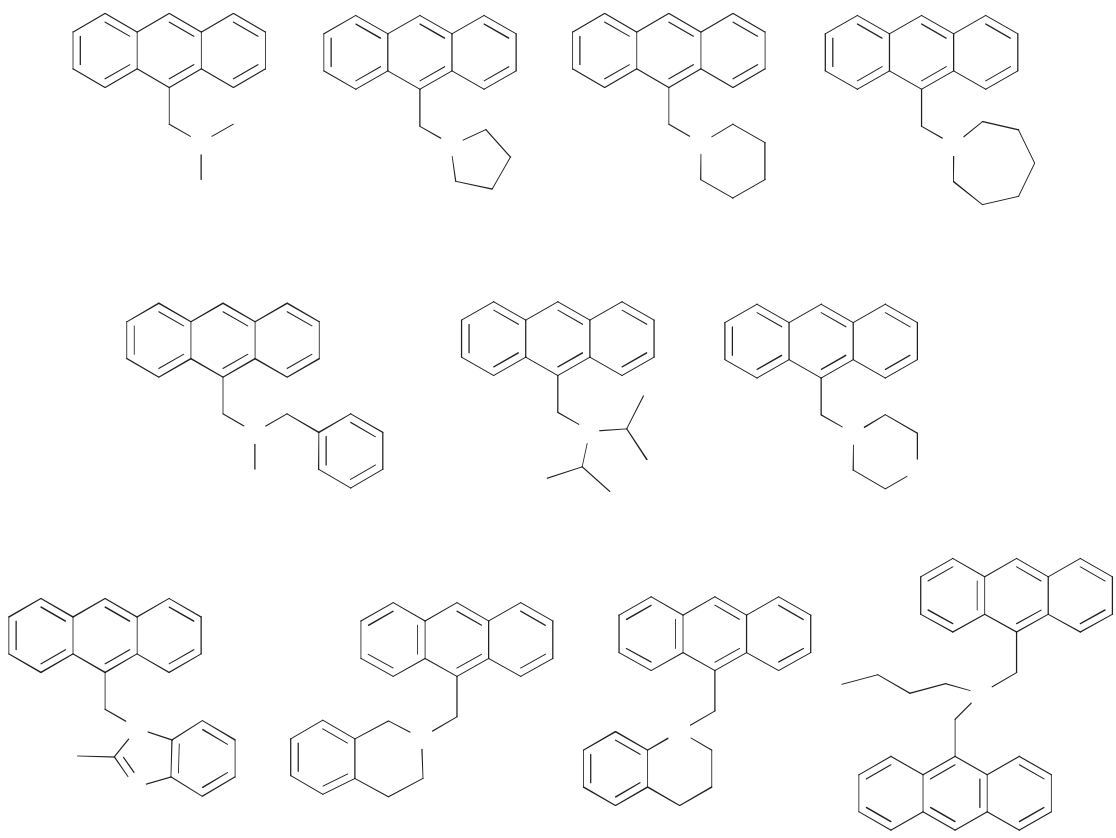

Chart 1. Structures of synthesised (anthracen-9-yl)methanamines.

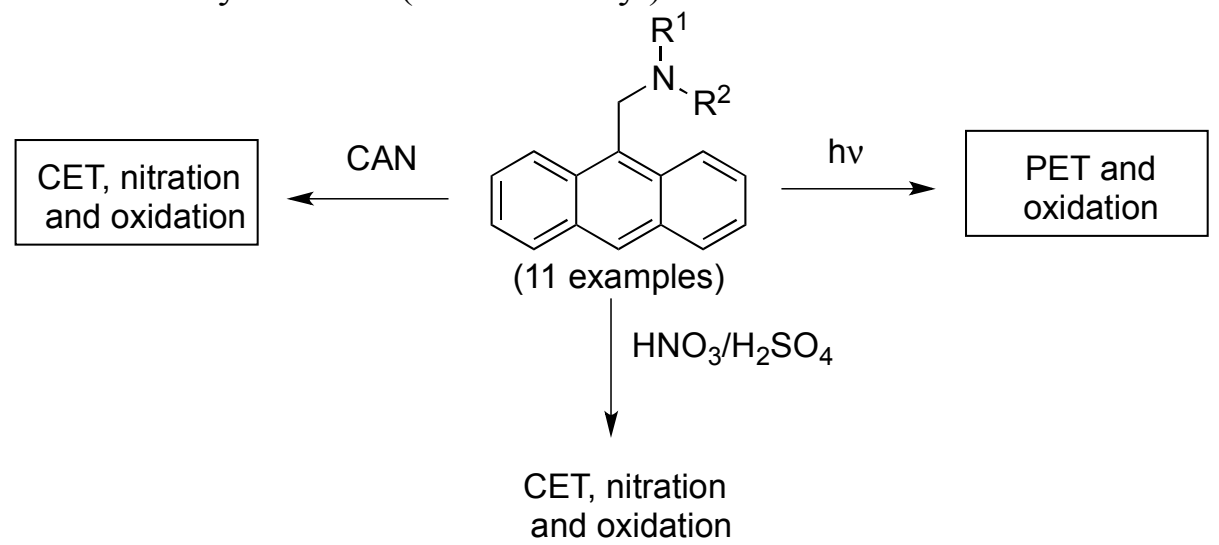

Chart 2. Reactions of anthracenemethanamines.

\section{Reaction of (anthracen-9-yl)methanamines with CAN.}

Reaction between 9-(N,N-dimethylaminomethyl)anthracene (1a) and CAN was carried out in a (5:1) mixture of acetonitrile and water and under reflux for four hours. Several products arising through a variety of reactions including single electron transfer from nitrogen (2), nitration $(3,4)$, oxidation (5) and nitration followed by oxidation $(\mathbf{6}, 7)$ were formed (Chart 3). To examine the effects of $N$-substituents in controlling the reaction between anthracenemethanamines and CAN, we repeated the reaction with (anthracen-9-yl)methanamines $\mathbf{1 b}-\mathbf{k}$. With $\mathbf{1 b}-\mathbf{k}$, we obtained identical products and the product distribution was virtually the same as obtained from 1a. In all 
reactions, C-N bond cleavage resulting in the formation of 9-anthraldehyde (2) and the corresponding secondary amine was observed as a minor reaction pathway. In reactions between 1a-g and CAN, we could not establish the generation of the corresponding secondary amine components. However, in the reaction of (anthracen-9-yl)methanamines $\mathbf{1 h}-\mathbf{k}$ having a significant amine component with CAN, corresponding secondary amines 8-11 could be isolated $^{7}$ (Chart 4).

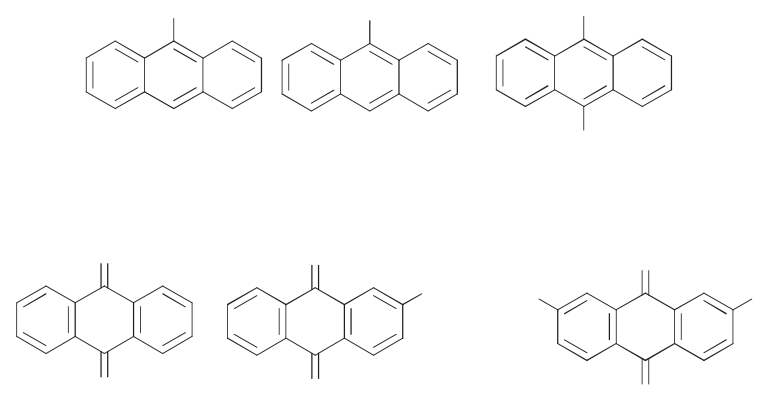

Chart 3. Products formed in the reaction between (anthracen-9-yl)methanamines and CAN.
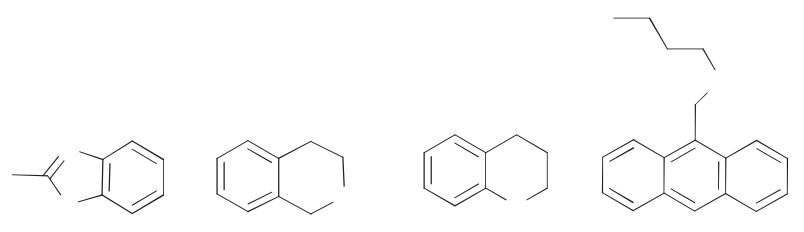

Chart 4. Secondary amines isolated from the reactions of $\mathbf{1 h}-\mathbf{k}$ with CAN.

In contrast to reported reactions between anthracenes and $\mathrm{CAN},{ }^{5,36-39}$ reaction of anthracenmethanamines with CAN resulted in regioselective nitration at the 2-position leading to products such as 6 and 7, suggesting a posssible role for the 9-methylamino group in controlling orientation in the reaction between anthracenemethanamines and CAN. To test this possibility, we reexamined the reaction between 9 -methylanthracene and $\mathrm{CAN} .{ }^{5}$ In contrast to previous reports, products 3-7 were exclusively generated as with 1a-k indicating an insignificant role for 9-methylamino group in controlling orientation of nitration. This experiment also indicated that the presence of a 9-methylamino substituent, is required for the formation of 9-anthraldehyde (2) through a mechanism unavailable for 9-methylanthracene. In continuation, we reexamined the reaction between anthracene and CAN. ${ }^{6}$ In this case also, in contrast to earlier reports, products such as 3-7 along with bianthronyl (12) were formed as with 1a-k revealing that even in the absence of a 9-substituent, for anthracenes, nitration at the 2-position is favored. In yet another control experiment, we observed that reaction between anthracene and a nitrating mixture 
$\left(\mathrm{HNO}_{3} / \mathrm{H}_{2} \mathrm{SO}_{4}\right)$ also gave products such as 3-7 in yields comparable to those obtained in the reaction with CAN. Thus it appears that a common mechanism is operating for these reactions. Single electron transfer from the anthracene component to the nitrating medium is possibly the first step in such reactions. However, in the case of anthracenemethanamines, concomitant electron transfer from the amine component to CAN followed by further transformation also occurs as a minor side reaction. The nature of $N$-substituents is insignificant in controlling reactivity of (anthracen-9-yl)methanamines towards CAN.

The structure of 7 was assigned on the basis of rigorous analysis of its ${ }^{13} \mathrm{C}$ NMR spectrum. In the ${ }^{13} \mathrm{C}$ NMR spectrum of 7, the two carbonyl carbons are not chemical shift equivalent ruling out a 2,6-dinitro substitution pattern. In order to check the intermediacy of 6 in the generation of 7, we treated 6 with excess CAN in a 5:1 mixture of acetonitrile and water. Unchanged 6 was recovered in quantitative amounts even after prolonged exposure to CAN. This experiment convincingly rules out the intermediacy of $\mathbf{6}$ in the formation of 7 in favor of species such as $\mathbf{1 3}$ and 15 respectively (Scheme 1). Oxidation of 13 and 15 to 6 and 7 may follow two distinct mechanisms. In a previous report, Rindone et al. ${ }^{6}$ proposed a mechanism involving a 9anthracenoxy radical to account for the generation of anthraquinone in the anthracene-CAN reaction. Similarly, anthraceneoxy radical 19 may be involved in the CAN-mediated oxidation of 1 (Scheme 1). In a control experiment, when a solution of $\mathbf{1}$ in 5:1 acetonitrile-water mixture was refluxed for four hours, anthraquinone was formed in trace amounts $(<2 \%)$. Based on this experiment, we conclude that formation of products such as 5, $\mathbf{6}$ and $\mathbf{7}$ is mostly by direct oxidation with CAN and, to an insignificant part, by direct oxidation of anthracenemethanamines with molecular oxygen. Our observation on direct oxidation is consistent with earlier reports on aerial oxidation of compounds such as 9,10-bis(1-hydroxyalkyl)anthracene and helianthrene. ${ }^{40-43}$

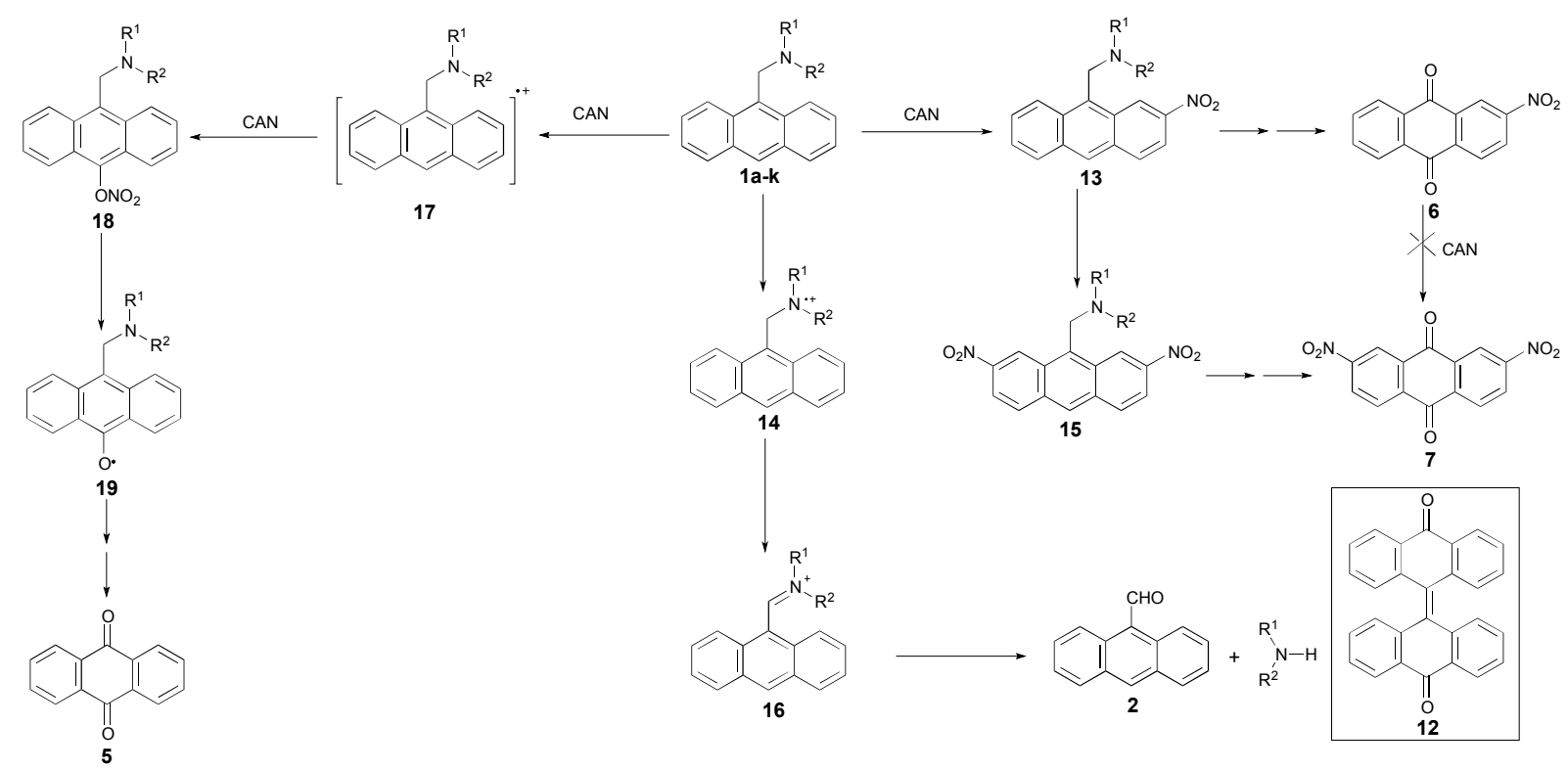

Scheme 1. Reaction between (anthracen-9-yl)methanamines and CAN. 


\section{Photoinduced electron-transfer reactions of (anthracen-9-yl)methanamines}

In continuation, we examined the photochemical transformations of anthracenemethanamines 1a-k. Previous reports on the irradiation of (anthracen-9-yl)methanamines at higher concentration $(>50 \mathrm{mM})$ indicated the formation of [4+4] adducts in major amounts. ${ }^{44}$ In order to suppress bimolecular reactions such as [4+4] adduct formation, we repeated the irradiation experiments at substantially lower concentrations ( $1 \mathrm{mM}$ in benzene) under argon using $350 \mathrm{~nm}$ lamps in a Rayonet photochemical reactor. Typically, the reaction was completed in seven hours and products obtained were separated, purified and characterised. 9-Anthraldehyde (2), 9,10anthraquinone (5), 9-methylanthracene (20), lepidopterene (21), ${ }^{45}$ 1,2-bis(9-anthracenyl)ethane (22) ${ }^{46,47}$ and biplanene (23) ${ }^{46-49}$ along with some polymerised materials were formed in the photolysis of 1a (Chart 5). Dimerization by [4+4] cycloaddition was not observed at this concentration.
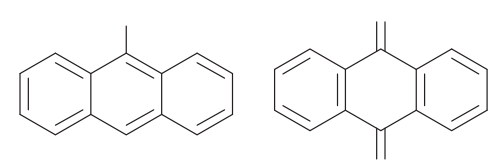

$10-14 \%$
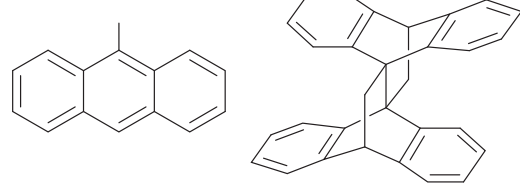

$25-32 \%$

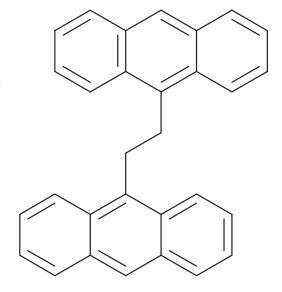

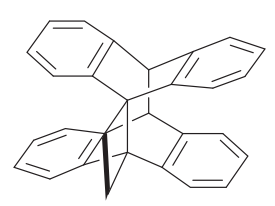

$13-17 \%$

Chart 5. Products formed by the PET reaction of (anthracen-9-yl)methanamines.

Based on products obtained from the photoreaction, we conclude that the anthracenemethyl radical is involved as an intermediate in the photochemical transformations of (anthracen-9yl)methanamines. ${ }^{15}$ Products such as 20, 21, 22 and 23 share common parentage of anthracenemethyl radical generated through intramolecular electron-transfer processes. ${ }^{15,16}$ If this is true, the rate of the photoreaction may depend on the electronic and steric environment around the nitrogen atom of (anthracen-9-yl)methanamines. In electron-transfer reactions, the rate of reaction is primarily decided by two processes viz. forward and back electron transfer. In the case of anthracenemethanamines electron availability on nitrogen and stabilization of incipient radical cation centre on nitrogen are crucial factors in controlling forward and back electron transfer, and hence, overall reaction rates. An attractive proposal is that the electronic and steric environment around nitrogen could control the efficiency of both forward and back electron transfer. In systems where electron availability on nitrogen is high and/or back electron transfer is inefficient, a faster reaction is anticipated.

To analyse the effect of steric and electronic environment around the nitrogen atom on the photoinduced electron-transfer reactions of (anthracen-9-yl)methanamines, we carefully studied the photoreactions of $\mathbf{1 b}-\mathbf{k}$ by supplying the same conditions as in the reaction of 1a. Upon exhaustive irradiation, $\mathbf{1 b}-\mathbf{k}$ gave the same products in near-identical yields as in the case of $\mathbf{1 a}$ (Chart 4). However, reaction times varied from substrate to substrate. As with the case of CAN 
mediated reactions, we could not establish the fate of the amine component in the photolysis of the (anthracen-9-yl)methanamines 1a-g presumably due to their loss as volatile fractions. Fortunately, in the irradiation of (anthracen-9-yl)methanamines having significant amine component such as $\mathbf{1 h}-\mathbf{k}$, corresponding secondary amines 8-11 were formed in isolable amounts (Chart 4).

Remarkable differences in reaction times were observed with 1a-k. Normally, starting material was totally consumed in 6-7 hours. For $\mathbf{1 g}$ and $\mathbf{1 j}$, the reaction was comparatively faster and starting material was totally consumed in two hours. On the other hand, prolonged irradiation (15 hours) was required in the case of $\mathbf{1 h}$. On the basis of electron availability on nitrogen, one would expect lower efficiency for electron transfer in the case of $\mathbf{1 h}$ and $\mathbf{1} \mathbf{j}$ thanks to efficient delocalization of the nitrogen lone pair of electrons. The effect of electron deficiency is reflected in the slow reaction exhibited by $\mathbf{1 h}$. It may be noted that electron transfer in $\mathbf{1 h}$ destroys the aromaticity of the imidazole ring and hence is disfavoured. However, in the case of $\mathbf{1 j}$, it may be noted that a radical cation centre on nitrogen once generated is stabilized by resonance and hence back electron transfer in this case is not exigent. Similarly, suppression of back electron transfer in $\mathbf{1 g}$ having a morpholine component may account for fast photochemical reaction exhibited by it. Transannular electron hopping between ring oxygen and radical cation centre on nitrogen is a distinct possibility here. In other words, anthracenemethanamines where back electron transfer is suppressed are the ones that react faster. Notably, the steric environment around nitrogen appears insignificant in controlling the reaction rates.

The mechanism for the photochemical reaction of (anthracen-9-yl)methanamines 1a-k can be explained (Scheme 2) on the basis of intramolecular one-electron transfer in the excited state of (anthracen-9-yl)methanamines to form an intramolecular aminium radical cation-anthracene radical anion pair 24. This leads to the destabilization and cleavage of a $\mathrm{C}-\mathrm{N}$ bond to form the resonance stabilised $(\mathbf{2 7}(\boldsymbol{p})$ and $\mathbf{2 7}(\alpha))$ anthracenemethylene radical $(\mathbf{2 7})^{50}$ and an aminium radical. Hydrogen atom abstraction by $\mathbf{2 7}(\alpha)$ and aminium radical give 9 -methylanthracene (20) and corresponding secondary amine respectively. Lepidopterene (21) was formed by the $\alpha / p$ dimerization of $\mathbf{2 7}$ followed by intramolecular [4+2] cycloaddition of dimer $\mathbf{2 9}$. This is a thermal intramolecular [4+2] cycloaddition, a facile process even at room temperature. ${ }^{50}$ 1,2-Bis(9anthracenyl)ethane (22) is formed by the $\alpha / \alpha$ dimerization of 27. Subsequent intramolecular [4+4] cycloaddition of 22 initiated by stray light leads to the generation of biplanene (23). We observed slow isomerization of $\mathbf{2 2}$ to $\mathbf{2 3}$ upon exposure to ambient light. Formation of 9,10anthraquinone (5) is explained on the basis of the intermediacy of endoperoxide $\mathbf{2 6}$ formed by the reaction of singlet oxygen with 1a-k. ${ }^{51}$ Loss of $\alpha$-hydrogen from $\mathbf{2 4}$ followed by hydrolysis of the incipient iminium ion intermediate $\mathbf{2 5}$ accounts for the generation of 9-anthraldehyde (2) (Scheme 2). 


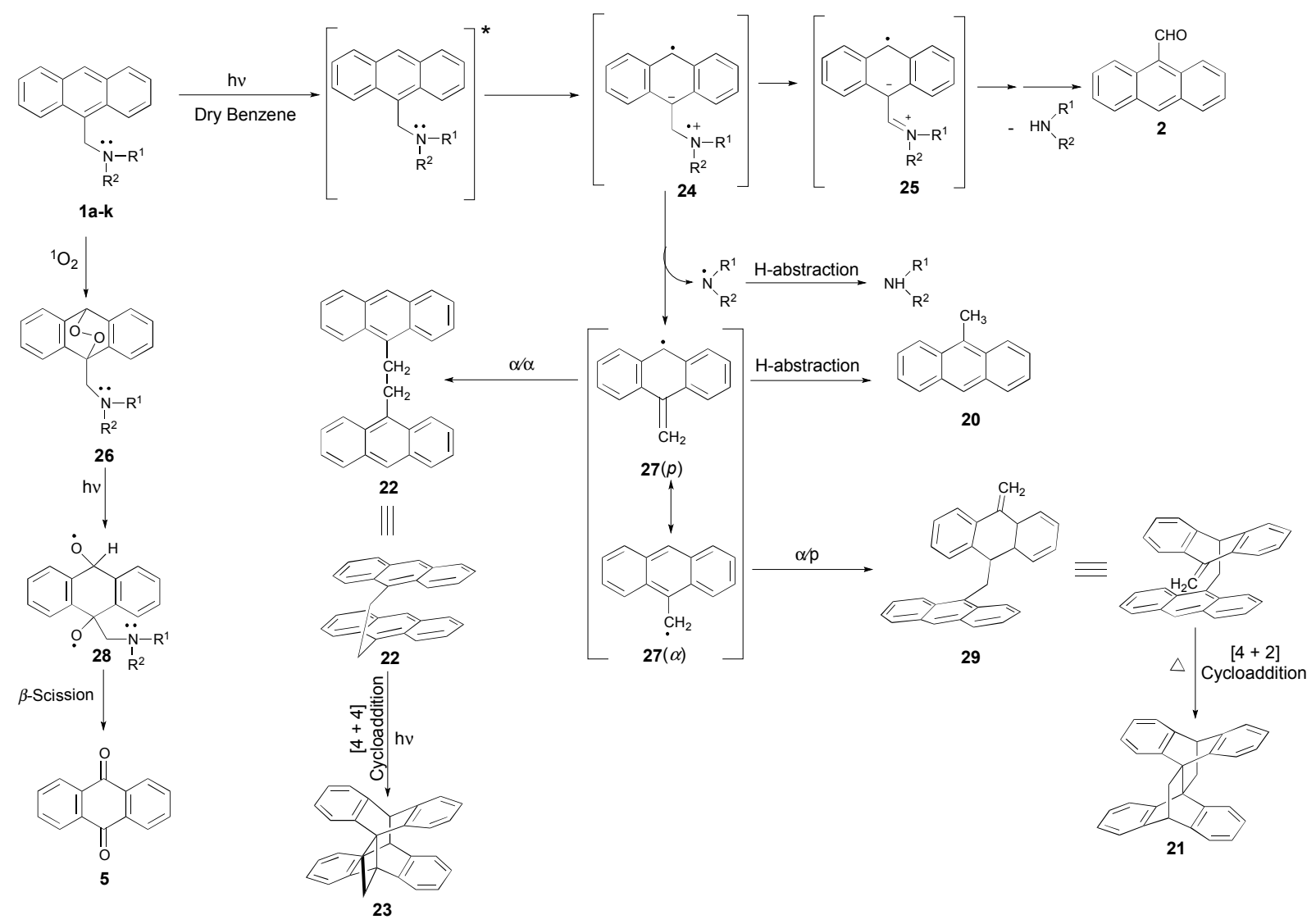

Scheme 2. PET mediated transformations of (anthracen-9-yl)methanamines.

\section{Conclusions}

Based on experimental results, it may be concluded that anthracenemethanamines exhibit dual reactivity towards CAN in the ground state: 1) intermolecular electron-transfer reactions from nitrogen to CAN (minor) and 2) nitration and oxidation like any other anthracene (major). Single electron transfer from anthracene to CAN is a distinct possibility here. For anthracenemethanamines, at lower concentrations, intramolecular electron transfer predominates in the excited state. Anthracenemethyl radical derived products dominate in the excited state reactions. 9-Anthraldehyde is a common product in CAN-mediated and light-induced reactions. Nature of electron transfer depends on reaction conditions. In the reaction between anthracenemethanamines and CAN, intermolecular single electron-transfer pathway is operating. On the other hand, under the influence of light, for anthracenementhanamines, intramolecular electron-transfer pathway is operating. 


\section{Experimental Section}

General.All reactions were carried out using oven-dried glasswares. All experiments used distilled and dried solvents by using standard protocols. All starting materials were purchased from either Sigma-Aldrich or Spectrochem Chemicals and were used without further purification. Progress of the reaction and chromatographic separations were monitored by dried and activated silica gel TLC plates (Aluminium sheets coated with silica gel, E. Merck). Visualisation of TLC plates was acquired by exposure to iodine vapours or UV lamp. Separation and purification of compounds were achieved by column chromatography using either silica gel (Spectrochem Chemicals, 60-120 mesh) or neutral alumina (Spectrochem Chemicals). The products were further purified by recrystallization from suitable solvent systems. Eluates from column chromatography were concentrated using Heidolph rotary evaporator. Melting points are uncorrected and were determined on a Neolab melting point apparatus. Infrared spectra were recorded using Jasco 4100 and ABB Bomem (MB Series) FT-IR spectrometers. The ${ }^{1} \mathrm{H}$ NMR spectra were recorded on a $400 \mathrm{MHz}$ FT-NMR spectrometer with tetramethylsilane (TMS) as internal standard. Chemical shifts $(\delta)$ are reported in parts per million (ppm) downfield of TMS. Elemental analysis was performed using Elementar Systeme (Vario EL III). Molecular mass was determined by electron impact (EI) method using GC-MS (Agilent GC-7890A, Mass-5975C) and fast atom bombardment (FAB) using JMS 600 JEOL mass spectrometer. Here we give only the spectral and analytical data for novel compounds; the corresponding reference is cited for known compounds.

Synthesis of (anthracen-9-yl)methanamines. (Anthracen-9-yl)methanamines 1a-k were prepared by Leukart and Leukart-Wallach reactions. ${ }^{15,35}$ (Anthracen-9-yl)methanamines 1a, ${ }^{52,53}$ $\mathbf{1 b},{ }^{53} \mathbf{1 c},{ }^{53,54} \mathbf{1 \mathbf { d } ^ { 5 3 }}$ and $\mathbf{1} \mathbf{g}^{53}$ are known compounds. Newly synthesized compounds $\mathbf{1 e}, \mathbf{f}, \mathbf{h}-\mathbf{k}$ were identified on the basis of spectroscopic and analytical data.

General procedure for the reaction of (anthracen-9-yl)methanamines with CAN. Ceric ammonium nitrate $(8.04 \mathrm{mmol})$ and (anthracen-9-yl)methanamines (1a-k, $3.80 \mathrm{mmol})$ were added to a mixture $(5: 1)$ of $\mathrm{MeCN}$ and $\mathrm{H}_{2} \mathrm{O}(15 \mathrm{~mL})$ and the mixture and was refluxed for $4 \mathrm{~h}$. Solvent was removed under reduced pressure and the residue was purified by column chromatography on silica gel. Elution with a mixture of hexane and $\mathrm{CH}_{2} \mathrm{Cl}_{2}$ (4:1) gave compounds $2, \mathbf{3}^{55}$ and $4{ }^{56}$ Elution with a mixture of hexane and $\mathrm{CH}_{2} \mathrm{Cl}_{2}(3: 2)$ yielded $\mathbf{5}$. Elution using a mixture of hexane and $\mathrm{CH}_{2} \mathrm{Cl}_{2}$ (3:7) yielded $6^{57}$ and $7 .{ }^{58}$

Reaction of 2-nitro-9,10-anthraquinone with CAN. Ceric ammonium nitrate $(8.04 \mathrm{mmol})$ and 2-nitro-9,10-anthraquinone $(6,3.80 \mathrm{mmol})$ were added to a mixture of $\mathrm{MeCN}$ and $\mathrm{H}_{2} \mathrm{O}(5: 1,15$ $\mathrm{mL}$ ) and the mixture and was refluxed. After $15 \mathrm{~h}$ unreacted 6 was recovered in near quantitative amounts. 
Reaction of 9-methylanthracene with CAN. Reaction of 9-methylanthracene (3.80 mmol) with ceric ammonium nitrate $(8.04 \mathrm{mmol})$ in a mixture of $\mathrm{MeCN}$ and $\mathrm{H}_{2} \mathrm{O}(5: 1,15 \mathrm{~mL})$ at $80{ }^{\circ} \mathrm{C}$ for 4 $\mathrm{h}$ yielded products such as $3(3 \%), 4(2 \%), 5(28 \%), 6(30 \%)$, and $7(3 \%)$.

Reaction of anthracene with CAN. Anthracene $(3.80 \mathrm{mmol})$ was reacted with ceric ammonium nitrate $(8.04 \mathrm{mmol})$ in a mixture of $\mathrm{MeCN}$ and $\mathrm{H}_{2} \mathrm{O}(5: 1,15 \mathrm{~mL})$ for $4 \mathrm{~h}$ at $80{ }^{\circ} \mathrm{C}$. Work-up of the reaction mixture yielded products such as $3(3 \%), 4(2 \%), 5(30 \%), 6(31 \%) 7(5 \%)$, and bianthronyl $(12,3 \%)$.

Reaction of anthracene with nitrating mixture. Anthracene $(3.80 \mathrm{mmol})$ was treated with nitrating mixture $\left(1: 1 \mathrm{HNO}_{3}-\mathrm{H}_{2} \mathrm{SO}_{4}, 1.5 \mathrm{~mL}\right)$ at $80{ }^{\circ} \mathrm{C}$ for $1 \mathrm{~h}$. Work-up of the reaction mixture yielded products such as $3(4 \%), 4(4 \%), 5(34 \%), 6(37 \%)$, and 7 (6\%).

Aerial oxidation of anthracenemethanamines. Solution of anthracenemethanamines 1a-k (3.80 mmol) in a mixture (5:1) of $\mathrm{MeCN}$ and $\mathrm{H}_{2} \mathrm{O}(15 \mathrm{~mL})$ and the mixture and was refluxed for $4 \mathrm{~h}$, providing the same conditions as in the above reactions. Work-up of the reaction mixture yielded anthraquinone $5(<2 \%)$ along with unreacted anthracenemethanamines.

General procedure for exhaustive irradiation of (anthracen-9-yl)methanamines.

A degassed solution of (anthracen-9-yl)methanamines (1a-k, 1 mM) in dry benzene was irradiated under argon atmosphere using $350 \mathrm{~nm}$ lamps. Progress of the reaction was monitored by TLC. Benzene was removed under reduced pressure and the residue was chromatographed over silica gel. Elution with a mixture (4:1) of hexane and $\mathrm{CH}_{2} \mathrm{Cl}_{2}$ gave compounds 4 and $\mathbf{2 0}$. ${ }^{59}$ Compounds $\mathbf{2 1},{ }^{45} \mathbf{2 2}^{46,47}$ and $\mathbf{2 3}^{46-49}$ were separated by elution with a mixture (7:3) of hexane and $\mathrm{CH}_{2} \mathrm{Cl}_{2}$. Further elution with a mixture $(3: 2)$ of hexane and $\mathrm{CH}_{2} \mathrm{Cl}_{2}$ yielded 5. In certain cases, elution with EtOAc gave the corresponding secondary amines. The reaction time depended on the nature of the (anthracen-9-yl)methanamines.

1-(Anthracen-9-yl)- $\boldsymbol{N}$-benzyl- $\boldsymbol{N}$-methylmethanamine (1e). Yield: $84 \%$; mp $116-118{ }^{\circ} \mathrm{C}$; IR $v_{\max }(\mathrm{KBr}): 3025,2822,1305,735 \mathrm{~cm}^{-1} ;{ }^{1} \mathrm{H}$ NMR $\left(\mathrm{CDCl}_{3}\right): \delta 8.54-7.28(\mathrm{~m}, 14 \mathrm{H}), 4.53(\mathrm{~s}, 2 \mathrm{H})$, $3.74(\mathrm{~s}, 2 \mathrm{H}), 2.28(\mathrm{~s}, 3 \mathrm{H}) ;{ }^{13} \mathrm{C} \mathrm{NMR}\left(\mathrm{CDCl}_{3}\right): \delta 139.4,131.5,131.4,130.4,129.0,128.2,127.5$, 127.0, 125.6, 125.1, 124.8, 62.5, 53.6, 42.2; MS: $m / z 311\left(M^{+}\right)$, 191, 92; Anal. Calcd for $\mathrm{C}_{23} \mathrm{H}_{21} \mathrm{~N}: \mathrm{C}: 88.71, \mathrm{H}: 6.80, \mathrm{~N}: 4.50$; Found: C: 88.75, H: 6.78, N: 4.47.

$\mathrm{N}$-(Anthracen-9-ylmethyl)- $\mathrm{N}$-isopropylpropan-2-amine (1f). Yield: $79 \%$; mp: $129-132{ }^{\circ} \mathrm{C}$; IR $v_{\max }(\mathrm{KBr}): 3051,2959,1350,750 \mathrm{~cm}^{-1} ;{ }^{1} \mathrm{H} \mathrm{NMR}\left(\mathrm{CDCl}_{3}\right): \delta 8.68-7.25(\mathrm{~m}, 9 \mathrm{H}), 4.67(\mathrm{~s}, 2 \mathrm{H})$, 3.03-2.94 (m, 2H), $1.14(\mathrm{~d}, 12 \mathrm{H}, J 8.8 \mathrm{~Hz}) ;{ }^{13} \mathrm{C} \mathrm{NMR}\left(\mathrm{CDCl}_{3}\right): \delta 131.9,131.8,131.6,128.0$, 127.1, 125.4, 125.0, 124.8, 46.7, 41.5, 21.1; MS: $m / z 291\left(M^{+}\right)$, 191; Anal. Calcd for $\mathrm{C}_{21} \mathrm{H}_{25} \mathrm{~N}$ : C: 86.55, H: 8.65, N: 4.81; Found: C: 86.50, H: 8.61, N: 4.60 .

1-(Anthracen-9-ylmethyl)-2-methyl-1H-benzo[d] imidazole (1h). Yield: 79\%; mp: 100-102 ${ }^{\circ} \mathrm{C}$; IR $v_{\max }(\mathrm{KBr}): 3056,2850,1348,1030,737 \mathrm{~cm}^{-1} ;{ }^{1} \mathrm{H}$ NMR $\left(\mathrm{CDCl}_{3}\right): \delta 8.59-6.83(\mathrm{~m}, 13 \mathrm{H})$, $6.17(\mathrm{~s}, 2 \mathrm{H}), 2.32(\mathrm{~s}, 3 \mathrm{H}) ;{ }^{13} \mathrm{C} \mathrm{NMR}\left(\mathrm{CDCl}_{3}\right): \delta 152.1,142.6,135.6,131.3,131.1,129.6,129.5$, 127.3, 125.3, 124.7, 123.1, 122.1, 121.7, 119.1, 109.9, 42.0, 15.4; MS: $m / z 323(\mathrm{M}+1), 191$; Anal. Calcd for $\mathrm{C}_{23} \mathrm{H}_{18} \mathrm{~N}_{2}$ : C: 85.68, H: 5.63, N: 8.69; Found: C: 85.59, H: 5.60, N: 8.59. 
2-(Anthracen-9-ylmethyl)-1,2,3,4-tetrahydroisoquinoline (1i). Yield: 77\%; mp: $128-130{ }^{\circ} \mathrm{C}$; IR $v_{\max }(\mathrm{KBr}): 3053,2760,1315,1012,745, \mathrm{~cm}^{-1} ;{ }^{1} \mathrm{H}$ NMR $\left(\mathrm{CDCl}_{3}\right): \delta 8.53-6.95(\mathrm{~m}, 13 \mathrm{H}), 4.61$ (s, 2H), 3.85 (s, 2H), 2.91-2.78 (m, 4H); ${ }^{13} \mathrm{C} \mathrm{NMR}\left(\mathrm{CDCl}_{3}\right): \delta$ 135.2, 134.7, 131.5, 131.5, 129.7, $128.9,128.6,127.5,126.6,126.0,125.7,125.5,125.2,124.9,56.2,53.9,50.5,29.3$; MS: $m / z 323$ $\left(M^{+}\right)$, 191, 146; Anal. Calcd for $\mathrm{C}_{24} \mathrm{H}_{21} \mathrm{~N}: \mathrm{C}: 89.12, \mathrm{H}: 6.54, \mathrm{~N}: 4.34$; Found: C: $89.00, \mathrm{H}: 6.45$, $\mathrm{N}: 4.29$.

1-(Anthracen-9-ylmethyl)-1,2,3,4-tetrahydroquinoline (1j). Yield: $64 \%$; mp: $163-165{ }^{\circ} \mathrm{C}$; IR $v_{\max }(\mathrm{KBr}): 3047,2770,1335,1030,7850 \mathrm{~cm}^{-1} ;{ }^{1} \mathrm{H} \mathrm{NMR}\left(\mathrm{CDCl}_{3}\right): \delta 8.47-6.73(\mathrm{~m}, 13 \mathrm{H}), 5.25(\mathrm{~s}$, 2H), 2.78-2.71 (m, 4H), 1.67-1.62 (m, 2H); ${ }^{13} \mathrm{C} \mathrm{NMR}\left(\mathrm{CDCl}_{3}\right): \delta 146.7,131.6,131.4,129.3$, 129.1, 128.5, 127.8, 127.3, 126.2, 125.1, 124.5, 123.9, 116.7, 110.7, 46.0, 44.8, 28.1, 22.5; MS: $m / z 323\left(M^{+}\right)$, 191, 132; Anal. Calcd for $\mathrm{C}_{24} \mathrm{H}_{21} \mathrm{~N}: \mathrm{C}: 89.12, \mathrm{H}: 6.54, \mathrm{~N}: 4.34$; Found: C: 89.02 , H: 6.49, N: 4.27 .

$\mathbf{N}, \mathbf{N}$-bis(Anthracen-9-ylmethyl)butan-1-amine (1k). Yield: $76 \%$; mp: $186-188{ }^{\circ} \mathrm{C}$; IR $v_{\max }$ (KBr): 3085, 2784, 1319, 1034, $795 \mathrm{~cm}^{-1} ;{ }^{1} \mathrm{H}$ NMR $\left(\mathrm{CDCl}_{3}\right): \delta 8.37-7.24(\mathrm{~m}, 18 \mathrm{H}), 4.58(\mathrm{~s}, 4 \mathrm{H})$, $2.64(\mathrm{t}, 2 \mathrm{H}, J 7.2 \mathrm{~Hz}), 1.71-1.64(\mathrm{~m}, 2 \mathrm{H}), 1.07-0.97(\mathrm{~m}, 2 \mathrm{H}), 0.60(\mathrm{t}, 3 \mathrm{H}, J 8 \mathrm{~Hz}) ;{ }^{13} \mathrm{C} \mathrm{NMR}$ $\left(\mathrm{CDCl}_{3}\right): \delta 131.5,131.4,130.6,128.8,127.4,125.4,125.2,124.7,54.5,50.8,29.2,20.6,13.7$; MS: $m / z$ 191; Anal. Calcd for $\mathrm{C}_{34} \mathrm{H}_{31} \mathrm{~N}$ : C: $90.02, \mathrm{H}: 6.89$, N: 3.09; Found: C: $90.03, \mathrm{H}: 6.89$, N: 3.08 .

\section{Acknowledgements}

We acknowledge STIC, Kochi for NMR and elemental analysis. JPJ and RG gratefully acknowledge CUSAT, Kerala Government and UGC for financial support in the form of Senior Research Fellowships. Funding for this work was provided by DST (PURSE and FIST schemes), UGC (SAP) and Kerala Government.

\section{References}

1. Molander, G. A. Chem. Rev. 1992, 92, 29. http://dx.doi.org/10.1021/cr00009a002

2. Nair, V.; Mathew, J.; Prabhakaran, J. Chem. Soc. Rev. 1997, 127.

3. Nair, V.; Deepthi, A. Chem. Rev. 2007, 107, 1862. http://dx.doi.org/10.1021/cr068408n

4. Sridharan, V.; Menendez, J. C. Chem. Rev. 2010, 110, 3805. http://dx.doi.org/10.1021/cr100004p

5. Zengin, M.; Sonmez, F.; Arslan, M.; Kucukislamoglu, M. Maced. J. Chem. Chem. Eng. 2012, 31, 55.

6. Rindone, B.; Scolastico, C. J. Chem. Soc. B 1971, 2238. 
http://dx.doi.org/10.1039/j29710002238

7. Bull, S. D.; Davies, S. D.; Fenton, G.; Mulvaney, A. W.; Prasad, R. S. ; Smith A. D. J. Chem. Soc., Perkin Trans. 1 2000, 3765.

http://dx.doi.org/10.1039/b006852g

8. O’Sullivan, S.; Doni, E.; Tuttle, T.; Murphy, A. J. Angew. Chem. Int. Ed. 2014, 53, 474. http://dx.doi.org/10.1002/anie.201306543

9. Lu, K.; Luo, T.; Xiang, Z.; You, Z.; Fathi, R.; Chen, J.; Yang, Z. J. Comb. Chem. 2005, 7, 958.

http://dx.doi.org/10.1021/cc050099b

10. Davies, G. S.; Fletcher, M. A.; Hughes, G. D.; Lee, A. J.; Price, D. P.; Roberts, M. P.; Russell, J. A.; Smith, D. A.; Thomson, E. J.; Williams, M. H. O. Tetrahedron 2011, 67, 9975. http://dx.doi.org/10.1016/j.tet.2010.10.067

11. Gore, G. M.; Sivabalan, R.; Nair, U. R.; Saikia, A.; Venugopalan, S.; Gandhe, B. R. Indian J. Chem. Sec. B 2007, 46, 505.

12. Evans, G. C.; Smith, C. M.; Carolan, P. J.; Gestwicki, E. J. Bioorg. Med. Chem. Lett. 2011, $21,2587$.

http://dx.doi.org/10.1016/j.bmcl.2011.02.079

13. Montero, M. L.; Rodríguez, D. A.; Gotor, V.; Fernández, G. V.; Lavandera, I. Green Chem. 2015; 17, 2794.

http://dx.doi.org/10.1039/C5GC00525F

14. Davies, G. S.; Lee, A. J.; Roberts, M. P.; Shah, S. R.; Thomson, E. J. Chem. Commun. 2012, $48,9236$.

http://dx.doi.org/10.1039/c2cc34808j

15. Jacob, J. P.; Gopalakrishnan, R.; Mallia, R. R.; Vadakkan, J. J; Unnikrishnan, P. A.; Prathapan, S. J. Phys. Org. Chem. 2014, 27, 884.

http://dx.doi.org/10.1002/poc.3351

16. Gopalakrishnan, R.; Jacob, J. P.; Mallia, R. R.; Vadakkan, J. J; Unnikrishnan, P. A.; Prathapan, S. J. Phys. Org. Chem. 2015, 28, 472.

http://dx.doi.org/10.1002/poc.3438

17. Sumalekshmy, S.; Gopidas, K. R. Chem. Phys. Lett. 2005, 413, 294.

http://dx.doi.org/10.1016/j.cplett.2005.06.041

18. John, R.; Smith, L.; Masheder, D. J. Chem. Soc., Perkin Trans. 2, 1976, 47.

19. Shono, T. Electroorganic Chemistry as a New Tool in Organic Synthesis, Springer, Berlin, 1982.

20. Ihmels, H.; Dirk Leusser, D.; Pfeiffer, M.; Stalke, D. Tetrahedron 2000, 56, 6867. http://dx.doi.org/10.1016/S0040-4020(00)00508-1

21. Horiguchi, M.; Ito, Y. J. Org. Chem. 2006, 71, 3608. http://dx.doi.org/10.1021/jo060315i

22. Basu, S. J. Photochem. 1978, 9, 539. http://dx.doi.org/10.1016/0047-2670(78)80169-5 
23. Halpern, A. M.; Wryzykowska, K. Chem. Phys. Lett. 1981, 77, 82.

http://dx.doi.org/10.1016/0009-2614(81)85605-9

24. Chandross, E. A.; Thomas, H. T. Chem. Phys. Lett. 1971, 9, 397. http://dx.doi.org/10.1016/0009-2614(71)80252-X

25. Beecroft, R. A.; Davidson, R. S. Chem. Phys. Lett. 1981, 77, 77. http://dx.doi.org/10.1016/0009-2614(81)85604-7

26. Bryce-Smith, D; Gilbert, A.; Klunklin, G. J. Chem. Soc., Chem. Commun. 1973, 330. http://dx.doi.org/10.1039/c39730000330

27. Davidson, R.S.; Bonneau, R.; Joussot-Dubien, J.; Toyne, K. J. Chem. Phys. Lett. 1979, 63, 269. http://dx.doi.org/10.1016/0009-2614(79)87015-3

28. Zachariasse, K; W. Kuehnle, W; Weller, A. Chem. Phys. Lett. 1978, 59, 375. http://dx.doi.org/10.1016/0009-2614(78)85002-7

29. Beecroft, R. A.; Davidson, R. S.; Whelan, T. D. J. Chem. Soc., Chem. Commun. 1978, 911. http://dx.doi.org/10.1039/c39780000911

30. Carter, F. L.; Siatkowshi, R. E.; Wohltjen, H. (Ed) Molecular Electronic Devices, Elsevier, Amsterdam, 1988.

31. Bissell, R. A.; de Silva, A. P.; Gunaratne, H. Q. N.; Lynch, P. L. M.; Maguire, G. E. M.; Sandanayake, K. R. A. S. Chem. Soc. Rev. 1992, 21, 187.

http://dx.doi.org/10.1039/cs9922100187

32. Fabbrizzi, L.; Poggi, A. Chem. Soc. Rev. 1995, 24, 197. http://dx.doi.org/10.1039/cs9952400197

33. de Silva, A. P.; Gunaratne, H. Q. N.; Gunnlaugsson, T.; McCoy, C. P.; Maxwell. P. R. S.; Rademacher, J. T.; Rice, T. E. Pure Appl. Chem. 1996, 68, 1443.

34. James, T. D.; Sandanayake, K. R. A. S.; Shinkai, S. Angew. Chem. Int. Ed. 1996, 35, 1910. http://dx.doi.org/10.1002/anie.199619101

35. Jacob, J. P.; Lalu, M. L.; Gopalakrishnan, R.; Mallia, R. R.; Vadakkan, J. J.; Prathapan, S.; Unnikrishnan, P. A. J. Adv. Res. Appl. Chem. Chem. Eng. 2014, 1, 1.

36. Nikishin, G. I.; Kaplan, E.P.; Kapustina, N. I. Russ. Chem. Bull. Int. Ed. 1975, 24, 1328.

37. Hui-qin, Z. Huaxue Shijie 2006, 286, 361.

38. Hui-qin, Z.; Jin-shun, L.; Feng-xia, Z. Huaxue Shijie 2007, 48, 428.

39. Tse-Lok, H.; Tse-Wai, H.; Wong, C. M. Synthesis 1973, 4, 206.

40. Dincturk, S.; Ridd, J. H. J. Chem. Soc., Perkin Trans. 2 1982, 965. http://dx.doi.org/10.1039/p29820000965

41. Seip, M.; Brauer, D. H. J. Am. Chem. Soc. 1992, 114, 4486. http://dx.doi.org/10.1021/ja00038a007

42. Marchand, P.; Srinivas, G.; Willian, H. W. Arkivoc 2003, (iii), 8.

43. Kuroda, S.; Oda, M.; Syumiya, H. Heterocycles 2004, 62, 153. http://dx.doi.org/10.3987/COM-03-S(P)24

44. Horiguchi, M.; Ito, Y. Tetrahedron 2007, 63, 12286. 
http://dx.doi.org/10.1016/j.tet.2007.09.069

45. Deardurff, L. A.; Alnajjar, M. S.; Camaioni, D. M. J. Org. Chem. 1986, 51, 3686. http://dx.doi.org/10.1021/jo00369a023

46. Adam, W.; Schneider, K.; Stapper, M.; Steenken, S. J. Am. Chem. Soc. 1997, 119, 3280. http://dx.doi.org/10.1021/ja963643g

47. Higuchi, H.; Otsubo, T.; Ogura, F.; Yamaguchi, H.; Sakata, Y.; Misumi, S. Bull. Chem. Soc. Jpn. 1982, 55, 182.

http://dx.doi.org/10.1246/bcsj.55.182

48. Vermeersch, G.; Febvay-Garot, N.; Caplain, S.; Couture, A.; Lablache-Combier, A. Tetrahedron Lett. 1979, 20, 609. http://dx.doi.org/10.1016/S0040-4039(01)86015-9

49. Felix, G.; Lapouyade,.R.; Castellan, A.; Bouas-Laurent, H.; J. Gaultier, J.; Hauw, C. Tetrahedron Lett. 1975, 16, 409. http://dx.doi.org/10.1016/S0040-4039(00)71879-X

50. Becker, H.-D.; Andersson, K.; Sandros, K. J. Org. Chem. 1980, 45, 4549. http://dx.doi.org/10.1021/jo01311a001

51. Danko, M.; Chmela, F.; Hrdlovic, P. Polym. Degrad. Stab. 2003, 79, 333. http://dx.doi.org/10.1016/S0141-3910(02)00297-5

52. Mulzera, J.; Huisgen, R.; Arionc, V.; Sustmannd, R. Helv. Chim. Acta. 2011, 94, 1359. http://dx.doi.org/10.1002/hlca.201100135

53. Vadakkan, J. J.; Mallia, R. R.; Prathapan, S.; Rath, N. P.; Unnikrishnan, P. A. Tetrahedron Lett. 2005, 46, 5919. http://dx.doi.org/10.1016/j.tetlet.2005.06.121

54. Devi, C. L.; Olusegun, O. S.; Kumar, C. N. S. S. P.; Rao, V. J.; Palaniappan, S. Catal. Lett. 2009, 132, 480. http://dx.doi.org/10.1007/s10562-009-0116-7

55. Adams, H.; Bawa, R. A.; McMillan, K. G.; Jones, S. Tetrahedron: Asymmetry 2007, 18, 1003 .

http://dx.doi.org/10.1016/j.tetasy.2007.04.012

56. Chawla, H. M.; Mittal, R. S. Synthesis 1985, 70. http://dx.doi.org/10.1055/s-1985-31110

57. Naeimi, H.; Namdari, R. Dyes Pigments 2009, 81, 259. http://dx.doi.org/10.1016/j.dyepig.2008.10.019

58. Yang, J.; Dass, A.; Rawashdeh, A. -M. M.; Sotiriou-Leventis, C.; Panzner, M. J.; Tyson, D. S.; Kinder, J. D.; Leventis, N. Chem. Mater. 2004, 16, 3457. http://dx.doi.org/10.1021/cm049526z

59. Susanto, W.; Chu, C, Y.; Ang, W. J.; Chou, T. C.; Lo, L. C.; Lam, Y. J. Org. Chem. 2012, 77, 2729. http://dx.doi.org/10.1021/jo202482h 